\title{
Schooling behaviour of small pelagic fish: phenotypic expression of independent stimuli
}

\author{
Patrice Brehmer ${ }^{1, *}$, François Gerlotto ${ }^{2}$, Charline Laurent ${ }^{1}$, Pascal Cotel ${ }^{3}$, \\ Alina Achury ${ }^{4}$, Birane Samb ${ }^{5}$ \\ ${ }^{1}$ Centre de Recherche Halieutique Méditerranéenne et Tropicale (IRD; IFREMER and University of Montpellier II), \\ 1 Avenue Jean Monnet, BP 171, 34203 Sète, France \\ ${ }^{2}$ Institut de Recherche pour le Développement, c/o Instituto del Mar del Peru, Esq. Gamarra y Gral Valle s/n, Chucuito, \\ La Punta, Callao, Peru \\ ${ }^{3}$ Institut de Recherche pour le Développement, Sainte Clotilde, 97490, île de La Réunion, France
}

${ }^{4}$ Fundación La Salle, Estación de Investigaciones Marinas Isla Margarita, Isla de Margarita, Punta de Piedras 6318, Venezuela

${ }^{5}$ Institut Sénégalais de Recherche Agronomique, Centre de Recherche Océanographique de Dakar-Thiaroye, BP 2241, Senegal

\begin{abstract}
We compared echo sounder measurements of fish schools on Venezuelan and Senegalese coastal shelves. In both areas Sardinella aurita was the predominant aggregative species; the stocks are known to be genetically independent. Persistent school typology is described by analysing 7 acoustic surveys in Venezuela and comparing with pioneer observations in Senegal. The echo types encountered in both countries were comparable, with $S$. aurita and their associated species having comparable schooling behaviour. School morphology appears to be more related to species than to global characteristics of their ecosystems, as fish school descriptors were similar for both stocks. Nevertheless, $S$. aurita may adopt different school morphologies. Differentiation between day and night fish schools was mainly due to morphological variables, as determined by fractal dimension. Echo types were different between day and night in both Venezuela and Senegal. This analysis shows that several independent parameters can influence school morphology. However, although schooling behaviour is temporally highly variable, it shows several constant, typical 2D morphological structures, i.e. echo types. The observation of small pelagic fish schools occurring during the night is not unusual according to the literature, although a strict diurnal schooling behaviour, with scattering during the night, is often reported. Schooling behaviour appears to be a phenotypic expression depending on biotic and abiotic stimuli, intrinsic characteristics and motivation.
\end{abstract}

KEY WORDS: Behaviour - Diel cycle - Echo type - In situ observations - Phenotypic expression · Schooling $\cdot$ Small pelagic fish

Resale or republication not permitted without written consent of the publisher

\section{INTRODUCTION}

The aggregation patterns of small pelagic fish produce clusters of fish schools where most of the biomass is concentrated. Describing such aggregative patterns is essential to modelling of the in situ schooling behaviour of fish (Azzali et al. 1985, Viscido et al. 2004). Schooling behaviour must be considered in the management of fisheries of pelagic species because of its impact on the estimation of catchability coefficients
(Marchal \& Petitgas 1993, Hjellvik et al. 2004). Nevertheless, in situ measurements of basic behaviour, such as schooling and diel aggregative patterns, are complex to obtain and to interpret. The most common diel schooling pattern of small pelagic species consists of fish scattering during the night and gathering in schools during the day (Shaw 1961, Blaxter \& Holliday 1969, Muiño et al. 2003, Milne et al. 2005) although there are numerous exceptions (Bertrand et al. 2004, 2006). 
Acoustic survey methods commonly employed in pelagic fisheries can be used to explore fish schooling behaviour, providing standardized in situ samplings of schools (Fréon \& Misund 1999, Simmonds \& MacLennan 2005). Using acoustic surveys, Petitgas \& Levenez (1996) demonstrated the existence of different schooling patterns within a fish community, establishing an 'echo type classification' of schools in the Senegalese small pelagic fish community. In this study, to determine whether these results are relevant to other communities, we performed a comparative analysis of schooling behaviours of similar fish assemblages from different geographical areas. Following definitions by Gerlotto et al. (2004), we studied school 'morphology', represented by external and global school characteristics (e.g. overall dimensions) and school 'structure', defined by the internal arrangement of individual fish inside schools, e.g. vacuoles and nuclei. Continuous in situ acoustic measurements of diel schooling behaviour of small pelagic fish (Fréon et al. 1996, Bertrand et al. 2004) were obtained from the same vessel in Senegalese and Venezuelan waters (Brehmer 2004). A comparative approach employing 2 different acoustic methodologies allowed comparison of school morphologies in 2 genetically independent tropical fish populations (Chicki 1995). The questions addressed in this study were: (1) Is small pelagic fish school morphology the result of a given strategy to occupy a given space depending on the environmental conditions or a simple phenotypic expression? (2) Do independent stocks of fish share similar diel schooling dynamics?

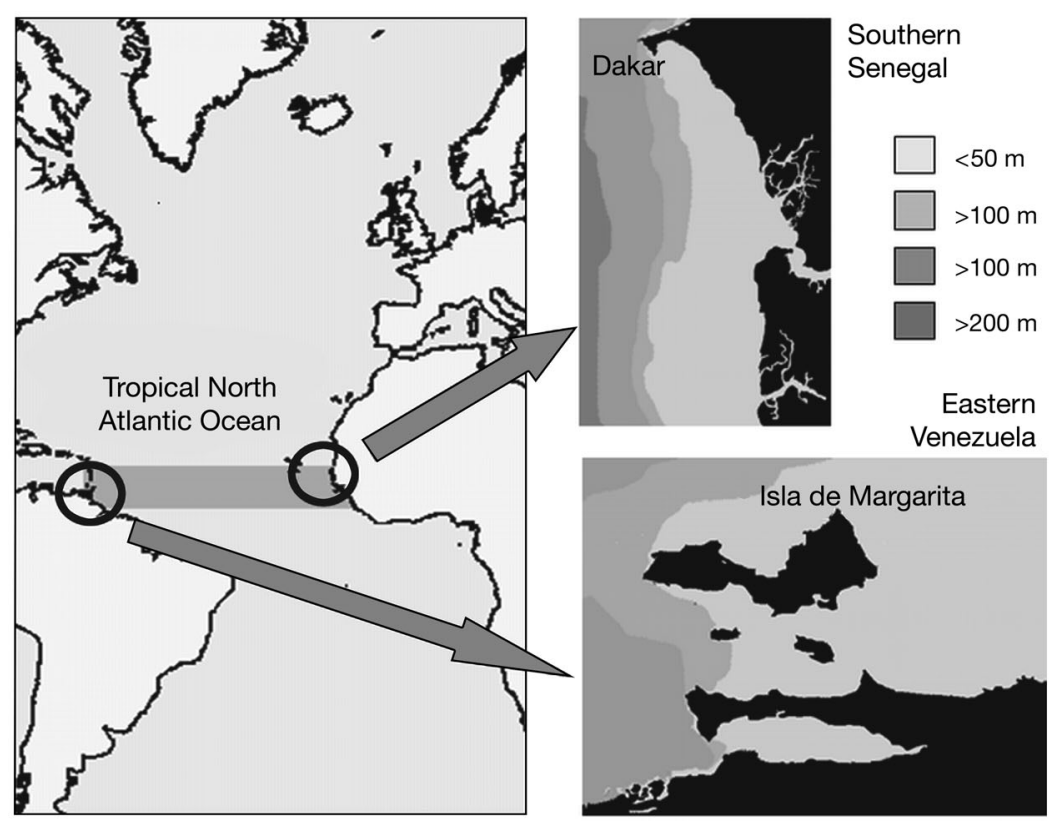

Fig. 1. The study areas, situated in the northern tropical Atlantic Ocean. Sardinella aurita constitute the main small pelagic schooling species, with 2 independent stocks: Eastern Venezuela and Southern coast of Sénégal

\section{MATERIALS AND METHODS}

Comparative approach using 2 independent fish stocks. The study areas were situated on both edges of the northern tropical Atlantic Ocean, in shelf waters of Senegal and Venezuela (Fig. 1). Sardinella aurita is a dominant schooling planktivore in the Eastern Venezuela and South Senegalese continental shelves (Fréon \& Mendoza 2003). Among the ca. 20 most common pelagic species in Senegal (engraulids, clupeids, carangids, scombrids) the main commercial landings are of $S$. aurita, followed by Engraulis encrasicolus, Ethmalosa fimbriata, and Sardinella maderensis. In Venezuela, there are at least 67 different small pelagic species (16 engraulids, 14 clupeids, 29 carangids, 8 scombrids) but the bulk of the biomass consists of 4 clupeids ( $S$. aurita, Harengula clupeoa, Etrumeus teres, Opisthonema oglinum), 1 anchovy (Cetengraulis edentulus), 3 horse mackerels (Trachurus lathami, Decapterus punctatus and Selar crumenophtalmus) and 1 scombrid (Scomber japonicus) species. In both countries, $S$. aurita represents ca. $80 \%$ of the pelagic biomass. Three sets of acoustic data were used, including the original echo traces of Petitgas \& Levenez (1996). Echo type classifications obtained from the Venezuelan database were compared with the Senegalese results (Petitgas \& Levenez 1996). Also, fish school descriptors observed on both fish stocks (S: Sénégal; V: Venezuela) were compared between night and day hours.

Classification of Venezuelan small pelagic fish echo types. An acoustic database from the eastern Venezuelan coastal shelf was compiled by combining data from 7 surveys (Table 1). A Simrad EKS or EK 400 echo sounder was used. Both echo sounders emitted at $38 \mathrm{kHz}$ with a pulse length of $0.6 \mathrm{~ms}$ and a Time Varied Gain function in 20 Log R. An Agenor echointegrator was used. The entire Venezuelan database included a total of 7736 single Elementary Sampling Distance Units $(E S D U=1$ nautical mile) with a predominant echo type structure, over a total of $14500 \mathrm{n}$ mile analysed.

Visual analysis of fish school targets on echograms, as defined by Petitgas \& Levenez (1996), was employed to classify echo types. Petitgas \& Levenez (1996) applied this visual echo classification to a set of 4 Senegalese acoustic surveys representing 3794 ESDUs. Nine school types were defined: (1) small schools 'SSM', (2) tower shaped schools 
Table 1. List of acoustic surveys used to constitute the Venezuelan data base for echo type classification, with 14500 Elementary Sampling Distance Units of $1 \mathrm{n}$ mile. The Varget surveys were used for echo integration by shoal processes (6236 fish schools)

\begin{tabular}{|c|c|c|c|c|c|c|c|}
\hline Survey & Year & Country & RV & Sounder & Echointegrator & $\mathrm{n}$ & Data process \\
\hline Echoven2 & 1986 & Venezuela & Capricorn & EKS & Agenor & 4032 & \multirow{7}{*}{$\begin{array}{l}\text { Echo type } \\
\text { discrimination } \\
\text { by ESDU }\end{array}$} \\
\hline Ecoven3 & 1985 & Venezuela & La Salle & EKS & Agenor & 2062 & \\
\hline Ecoven 4 & 1986 & Venezuela & La Salle & EKS & Agenor & 2401 & \\
\hline Ecoven5 & 1986 & Venezuela & La Salle & EKS & Agenor & 965 & \\
\hline Ecoven6 & 1987 & Venezuela & La Salle & EKS & Agenor & 2109 & \\
\hline Fepelor1 & 1988 & Venezuela & La Salle & EKS & Agenor & 1406 & \\
\hline Fepelor2 & 1988 & Venezuela & La Salle & EK 400 & Agenor & 1525 & \\
\hline Varget1 & 1999 & Sénégal & Antéa & EK 500 & Movies+ & 4606 & \multirow{2}{*}{$\begin{array}{c}\text { Echointegration } \\
\text { by shoal }\end{array}$} \\
\hline Varget2 & 1999 & Venezuela & Antéa & EK 500 & Movies+ & 1630 & \\
\hline
\end{tabular}

'STW', (3) compact schools 'SCO', (4) pole shaped schools 'SPO', (5) fluffy schools 'SFL', (6) zigzag shaped schools 'SZZ', (7) thermocline shaped layers 'LT', (8) macro structures 'MS' (not used by Petitgas \& Levenez 1996 because they were too infrequent) and (9) scattered fish 'FS'. In an ESDU more than one target type can be recorded. In such cases, the corresponding ESDU was included in the dominant structure category. Several ESDU can have no echo types, although they may contain echoes that cannot be classified into any existing type. These ESDU were included in the no structure category 'NS' with the FS echo types. Inside the same ESDU, a dominant echo type can become another, e.g. SZZ may become LT and vice versa. In this case we grouped both echoes under the SZZ category. The comparison between echo types encountered in both Senegal and Venezuela was computed by a chisquare test on their proportion values (Gonzalez et al. 1998). After the pioneering work of Petitgas \& Levenez (1996), data bases could now be enriched thanks to improved performance of echo sounders and automatic digital recording and processing of echograms.

In situ observations of Senegalese and Venezuelan fish schools. Two acoustic experimental surveys were made using the RV 'Antéa', with the same echo sounder (Simrad EK500, $38 \mathrm{kHz}$ ) and the same sampling methods in both Senegalese (average SST: $24.0^{\circ} \mathrm{C}_{\text {; }}$ average bottom depth: $35 \mathrm{~m}$ ) and Venezuelan (average SST: $25.2^{\circ} \mathrm{C}$; average bottom depth: $33 \mathrm{~m}$ ) continental shelf waters (Brehmer 2004). The experiments were performed during the season of highest Sardinella aurita abundance at both locations (Fréon \& Mendoza 2003). Surveys consisted of transects perpendicular to the coastline along the coastal shelf at a constant speed of 8 knots. The calibrated echo sounder pulse length was $1 \mathrm{~ms}$ and its Time Varied Gain function (TVG) was set at 20 Log R. After post-processing (see next paragraph), in situ observations of a total of 6236 fish schools were made during several continuous diel cycles records (Venezuela $n=1630$; Sénégal $n=$
4606). Short term variability and circadian changes were taken into account, and night and day periods were differentiated (Fréon et al. 1996).

The 'echo integration by shoal' process was employed (Scalabrin \& Massé 1993, Petitgas et al. 2001, Guillard et al. 2004), which did not take into consideration the individual fish but rather the structure of fish schools, employing the echo types defined above. Graphical measure corrections on fish schools were carried out according to Johannesson \& Losse (1977). Corrections were incorporated into 'Movies+' software (Weill et al. 1993) and all 'false' and doubtful detections (acoustic interference, bottom echoes, ship records adrift) were removed. Fish school descriptors were taken (Fig. 2) and categorised in 3 groups: (1) morphological: length ' $L$ ' $(\mathrm{m})$, height ' $H$ ' $(\mathrm{m})$, perimeter ' $P^{\prime}(\mathrm{m})$, surface area ' $A$ ' $\left(\mathrm{m}^{2}\right)$, elongation ' $E l^{\prime}(L / H)$ and fractal dimension ' $F$ ' $(2 \times \log (\mathrm{P} / 4) / \log \mathrm{A})$; (2) spatial: minimum depth ' $D_{\min }$ ' $(\mathrm{m})$, minimum altitude (i.e. distance to the bottom) ' $A_{\min }$ ' (m) and local depth ' $D$ ' (m); (3) acoustic: energy volume ' $E n^{\prime}\left(\mathrm{m}^{2}\right)$ and corrected mean volume backscattering strength ' $S v^{\prime}(\mathrm{dB})$ as:

$$
S V=10 \log \left(\frac{E n}{A}\right)
$$

Fish schools were identified by attributing maximum and minimum values of 5 descriptors: $2 \times 10^{-6}<E n<$ $100 \times 10^{6}, 1<H<500,1<L<1000,2<A<500$ and $S V$ greater than $-55 \mathrm{~dB}$. Descriptors were set in order to eliminate small-sized schools, which are surely not composed of Sardinella aurita, and to avoid fake schools due to noise and backscatter. Fish schools with mean depth values between $20 \mathrm{~m}$ and $100 \mathrm{~m}$ were removed from the analysis, in order to limit the effects of avoidance behaviour on the measurement of fish school descriptors (Vabø et al. 2002) and to restrict observations to schools of $S$. aurita. To evaluate the effects of location and diel periods (day/night) a principal component analysis (PCA) of fish school descriptors was performed, using the statistical software ' $R$ ' 


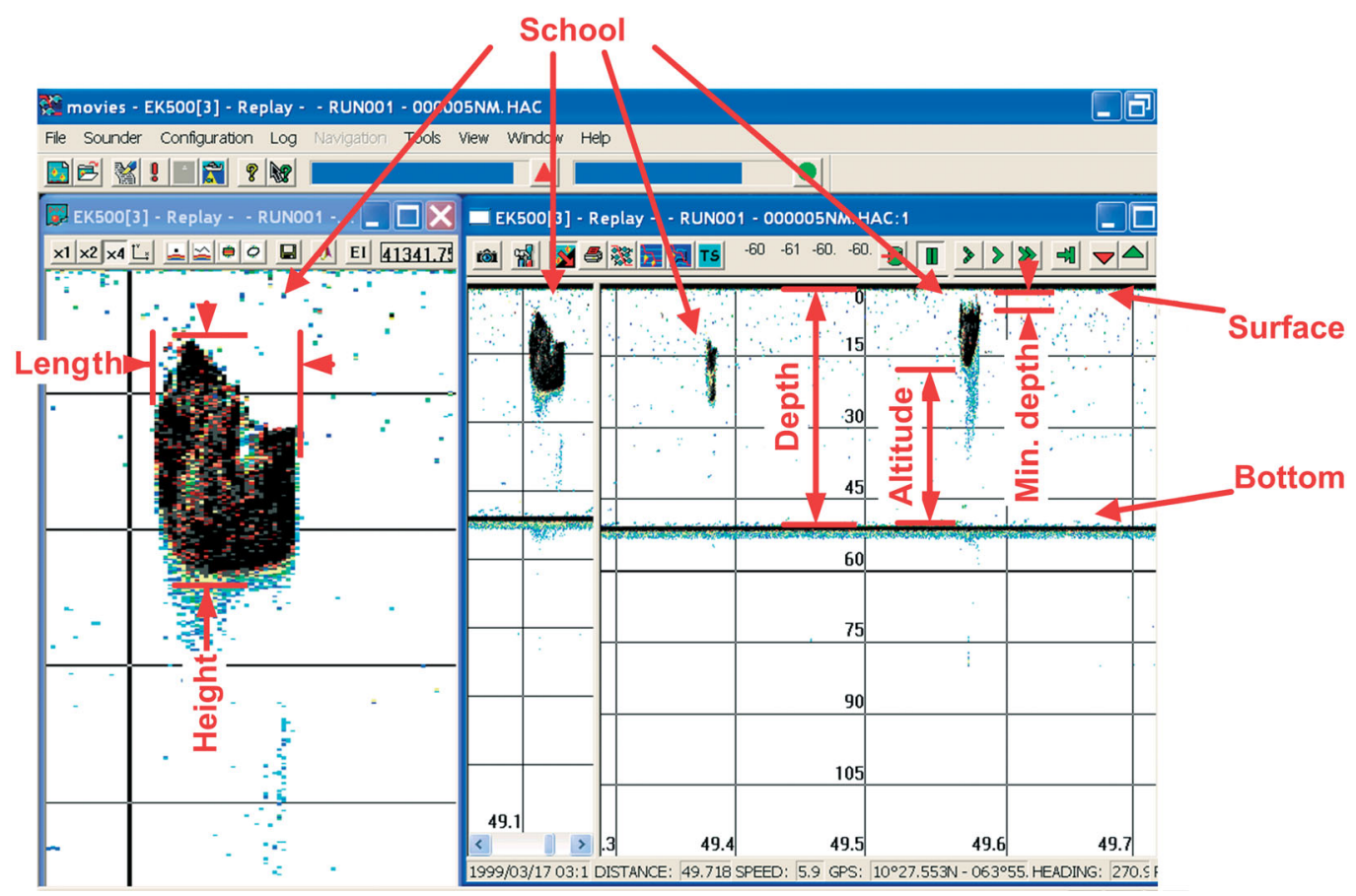

Fig. 2. Echo integration by shoal (Weill et al. 1993) on both independent stocks, using the same measurement methodology, to obtain fish school morphology: length $L(\mathrm{~m})$, height $H(\mathrm{~m})$, perimeter $P(\mathrm{~m})$, surface area $A\left(\mathrm{~m}^{2}\right)$, elongation $E l(L / H)$ and fractal dimension $F$; acoustic characteristics: energy volume $E n\left(\mathrm{~m}^{2}\right)$ and corrected mean volume backscattering strength $S v(\mathrm{~dB})$; and vertical position: minimum depth $D_{\min }(\mathrm{m})$, minimum altitude $A_{\min }(\mathrm{m})$, local depth $D(\mathrm{~m})$

(http://cran.r-project.org). Eight variables gave nonredundant information (correlation between variables $<0.9$ ): $S_{V}$ (energetic descriptors), $H, L, E l$ and $A$ (morphologic descriptors) $A_{\min }$ and $D_{\min }$ (spatial descriptors). This allowed qualitative information to be taken into account, in terms of membership of a class for each observation, and revealed what differentiated the classes. The observations were divided into 4 classes: SN (Sénégal Night), SD (Sénégal Day), VN (Venezuela Night) and VD (Venezuela Day). From the PCA, 174 fish schools were identified as outliers and eliminated, in order to homogenize the logarithmic transformed data.

\section{RESULTS}

\section{Fish school echo types}

All the echo types defined in Senegal (Petitgas \& Levenez 1996) were found in the Venezuelan data set, except STW echo types, which represent $1.5 \%$ of the echo types encountered in Senegal (Petitgas \& Levenez 1996). Nevertheless, even though their presence was rare, we observed STW echo types (Brehmer 2004; Fig. 3) on echograms from the 1999 Venezuelan acoustic survey (Table 1). Other struc-

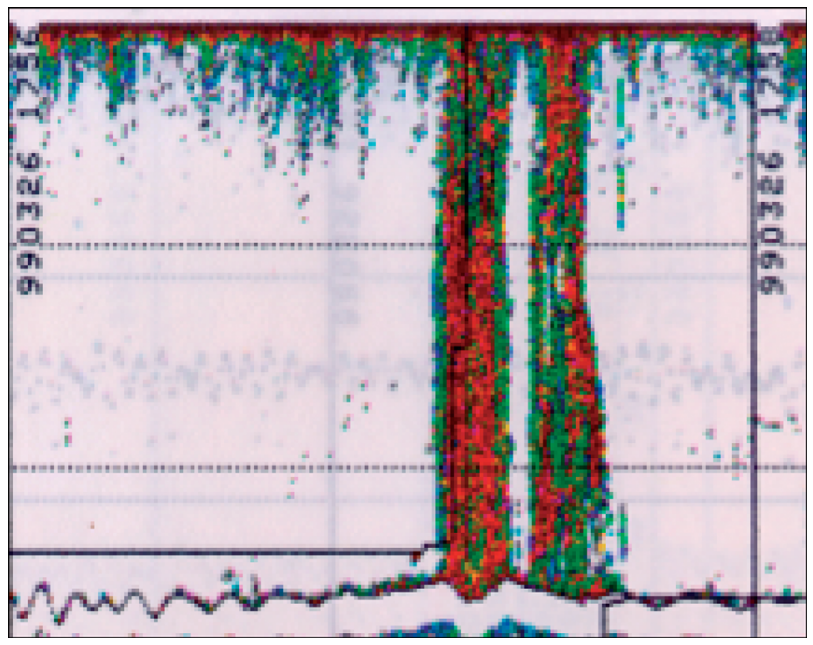

Fig. 3. Echo type STW ('tower schools') encountered on Venezuelan echogram in 1999 (Varget 2/99) but not during the 7 surveys between 1985 and 1988

tures were consistent with echo type from both countries (Fig. 4). The predominant echo type by ESDU was SSM $(29.7 \%$ in Sénégal and $26.5 \%$ in Venezuela) followed by SCO $(12.9 \%$ in Venezuela and $7.5 \%$ in Sénégal) and SFL (6.6\% in Venezuela and $6.8 \%$ in Sénégal). Rare echo types included SZZ 
( $4 \%$ of the population in Sénégal and $1.2 \%$ in Venezuela) and SPO (1.6\% in Sénégal and $0.2 \%$ in Venezuela). Schools with no ESDU structure were the most common echo type $(50.7 \%$ in Venezuela and $51.6 \%$ in Sénégal). The Senegalese (Petitgas \& Levenez 1996) and Venezuelan echo type proportions were similar (Fig. $5 ; \chi^{2}=8.98 ; \mathrm{p}<0.05$ ).

\section{Analysis of fish school descriptors}

Eigenvalues from the principal component analysis (Fig. 6A) showed that the first axis accounted for $77.8 \%$ of the variance, including fractal dimension (fractal, on the right), and height and area ( $H$ and $A$, on the left). The second axis was negatively related to elongation and corrected for length $(L)$ (Fig. 6B). The third axis was negatively related to the variable $A_{\min }$ (Fig. 6D).

VD and SD (Venezuela Day and Sénégal Day) were both negatively correlated with the first axis: whatever the region, the 'day' modality related to low fractal

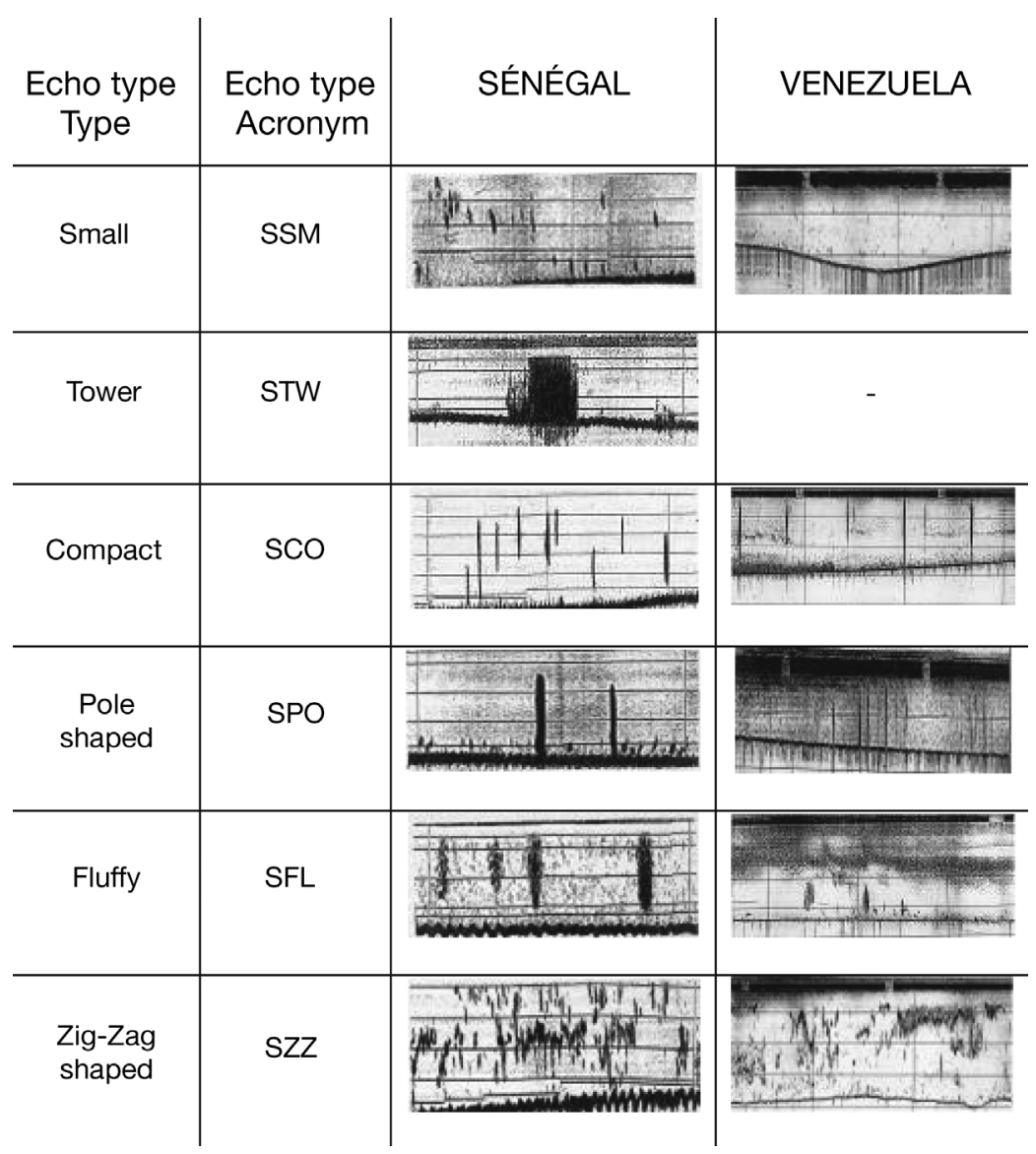

Fig. 4. Echo type names and acronyms encountered on the echogram from Senegal (Petitgas \& Levenez 1996). Identical echo types were observed in the Venezuela data base, in similar proportions dimension values. The 2 regions were distinguished during the day by the variables $L$ and $E l$ on the second axis. VD had low fractal dimension and low elongation and length corrected. SD had low fractal dimension and high elongation and length corrected.

The 'night' modality in the 2 regions (VN: Venezuela Night, SN: Sénégal Night) was situated on the positive side of the first axis: nightime fractal dimension values were higher, with the largest values for Sénégal. The 2 regions could also be distinguished during the night on the third axis (Fig. 6D). Fish schools observed in Venezuela during the night were therefore characterized by low $A_{\text {min }}$ values, whereas $\mathrm{SN}$ was characterized by high $A_{\min }$ values.

From the acoustic in situ observations, the percentage of fish schools detected during the night was $69.1 \%$ in Venezuela and $59.5 \%$ in Sénégal. The energetic fish school descriptor values decreased during the night in both regions, though not significantly (see details by school origin and diel period: Fig. 7).

\section{DISCUSSION}

\section{Schooling behaviour}

The echo type classification defined by Petitgas \& Levenez (1996) appears to be robust and allowed the discrimination of school echo types representing typical structures in the eastern Venezuela coastal shelf. Both Senegalese and Venezuelan fish school populations presented similar echo type structures in equivalent proportions. Moreover, no noticeable differences were found between the Venezuelan and Senegalese fish school descriptors, except for $A_{\min }$, a descriptor not characteristic of schooling behaviour. The higher $A_{\text {min }}$ values in Sénégal could reflect increased prey depth (Bertrand et al. 2006) or the effect of local bottom depth configuration in our survey transects. The length of fish schools and its variability was always larger than school height in both populations. The shape of both fish school populations was particularly stretched in the direction of the boat heading, demonstrating a fish school avoidance reaction in front of the surveying vessel (Brehmer et al. 2002), even over $20 \mathrm{~m}$ of bottom depth. School origin (Senegal or Venezuela) 


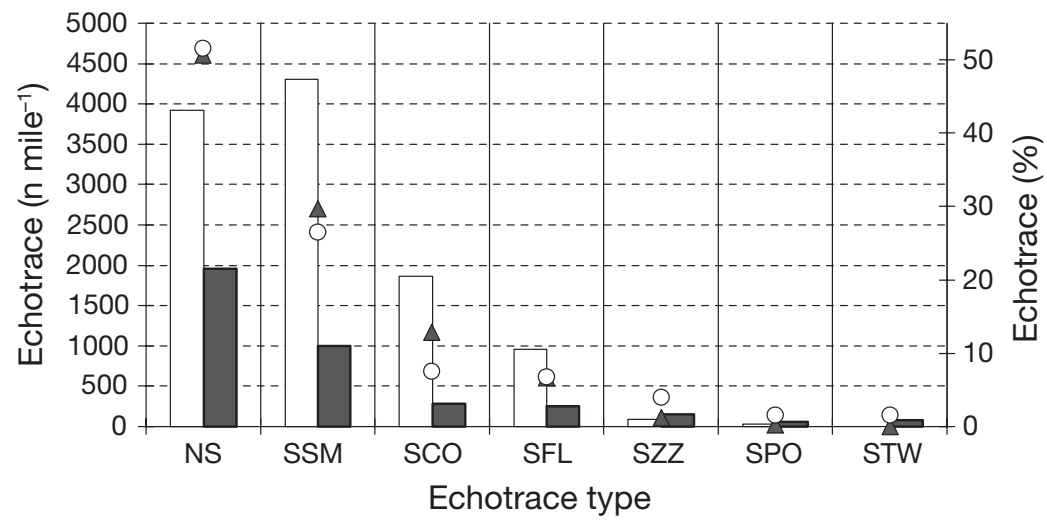

Fig. 5. Histogram of the main echo types observed in Venezuela (white) and Sénégal (grey), by nautical miles (n mile) and \% ( $\Delta$ : Venezuela; O: Sénégal). Echo types-NS: no identified structure; SSM: small schools; SCO: compact schools; SFL: fluffy schools; SZZ: zig-zag schools; SPO: pole-shaped schools; STW: tower schools

was discriminated during the day by its length and elongation and was in Sénégal (SD), where horizontal avoidance reactions were more frequently observed (Brehmer 2004).

The finding of similar echo types in 2 independent areas permits us to suggest 2 hypotheses: (1) small pelagic fish schools, regardless of species, have similar schooling behaviour in both locations; (2) the similarity observed is due to the same dominant species (mostly Sardinella aurita) in both fish assemblages. The abiotic environment (i.e. pelagic habitat) is likely to have a limited impact on small pelagic fish school morphology, as previously observed by Bahri \& Fréon (2000) for clupeids.

The echo characteristics of a fish school may correspond to specific criteria (Scalabrin 1997, Ohshimo
2004). SSM were the most common of the 5 echo types encountered in both locations, being present in $30 \%$ of the ESDUs in the overall data base. Sardinella aurita was the most prominent fish species present in the 2 areas (>80\%). Consequently, we cannot say that a single type is specific, but we certainly can assume that single species form different types of schools. Uncommon echo type categories may well consist of other associated schooling species, but no definitive answer can be given without an efficient species identification method. No echo type variation was observed over multiple years, either in Sénégal (Petitgas \& Levenez 1996), Venezuela (Gonzales et al. 1998) or in the Mediterranean Sea (Muiño et al. 2003), even though fish species composition has probably changed in these locations during this last decade. Moreover, Nøttestad et al. (1996) distinguished specific changes in characteristics of Clupea harengus schools during a spawning season. The schooling behaviour of a species, defined by its intrinsic characteristics and its interaction with environmental factors, can result in several school echo morphologies (Fig. 8). This finding is in agreement with observations by Gerlotto et al. (2004), who proposed that internal structures are stable while external morphologies are variable. Therefore monospecific schools could correspond to various echo types and a single echo type could correspond to several fish species. According to Parrish \& Edelstein-Keshet (1999) the 'optimal group size' fluctuates seasonally, daily and

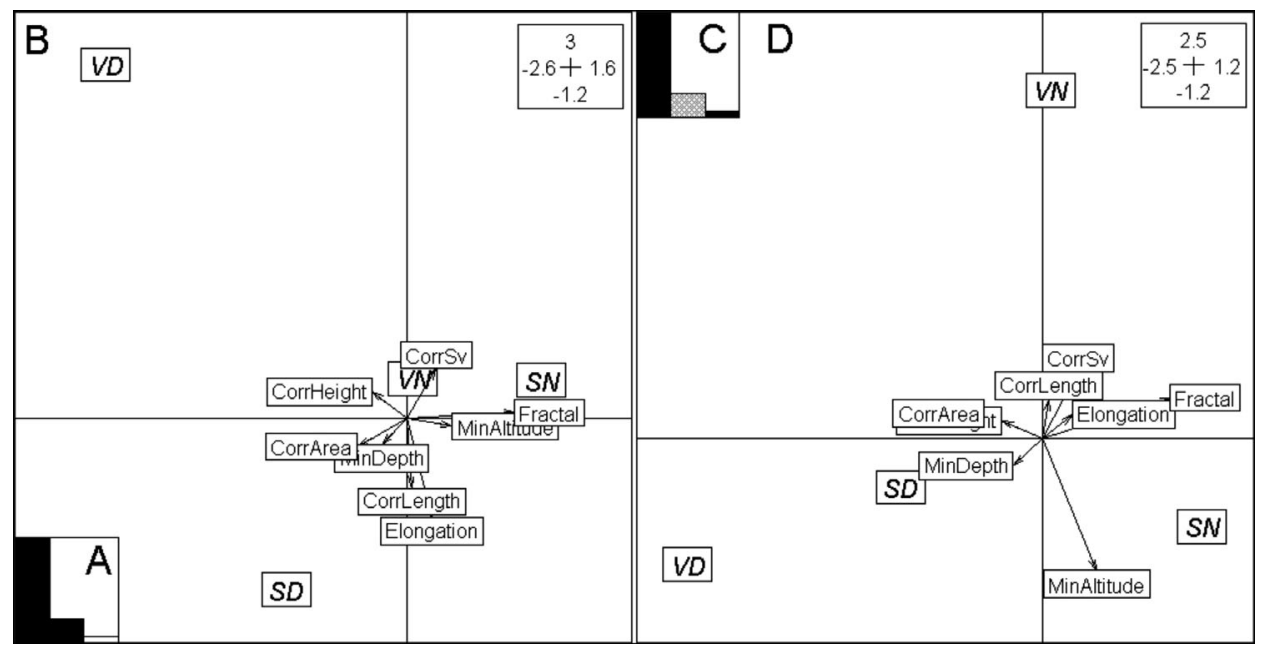

Fig. 6. (A \& C) Histograms of eigenvalues of fish school descriptors (see Fig. 2). S: Sénégal; V: Venezuela; D: day; N: night. (B \& D) Factor maps of centres of classes and superposition of school descriptors (B: Axis 1 \& 2; D: Axis 1 \& 3). Scale in box at top right 

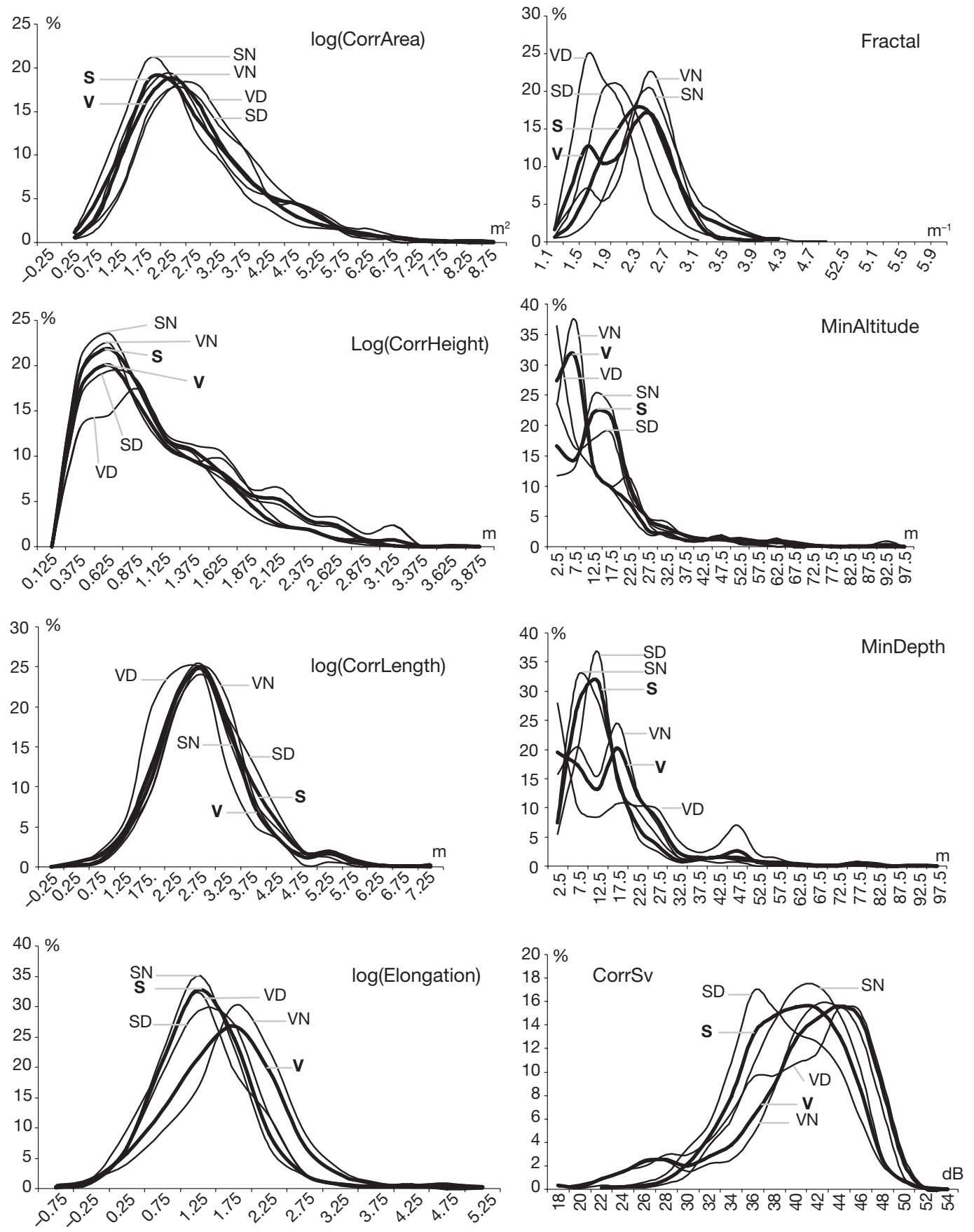

Fig. 7. Frequency curves of fish school descriptors (area, height, length, elongation, fractal dimension, minimum attitude, depth, mean volume backscattering strength) obtained in S: Sénégal and V: Venezuela, and by diel categories, D: day and N: night. Corr: descriptor is corrected; log: log transformed data

hourly, depending on predation pressure, food-patch size, individual hunger level and breeding stage. There were more pelagic schooling fish species (ca. 67 in Venezuela) than observed echo types.

Taxonomic discrimination by using echo type classification techniques may be restricted to the level of fish families. When several species coexist in the same habitat, we may not expect the development of precise and automatic species identification methods by analyzing school morphologies. Nevertheless the typology of fish schools is an indicator of the relationships between the pelagic fish communities and environmental features. Rose \& Legget (1988) and Gerlotto (1993) showed that school type proportions can 


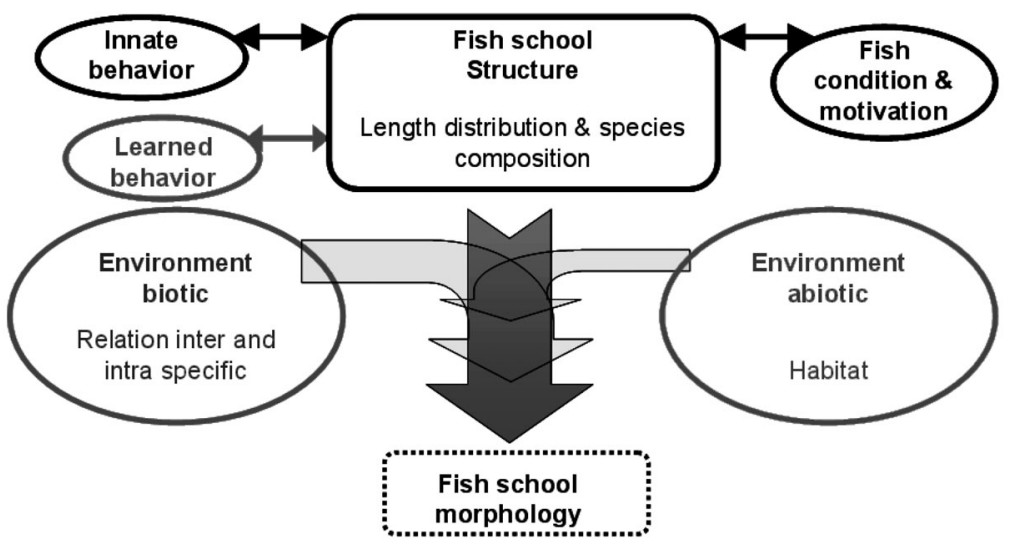

Fig. 8. Representation of the main variables suspected to play a role in schooling behaviour. School morphology is a phenotypic expression of innate behaviour, which depends on school structure characteristics, defined by the school member length distribution and species composition variability; condition and motivation, determined by the effect of biotic and abiotic components of the environment (i.e. inter- and intra-specific relations and spatiotemporal variation of the habitat); and the possibility of learning processes in response to the environment

help to characterize an area occupied by a pelagic community. In our study, even if the relative abundance of fish species varied between the 2 study areas, the spatial distribution of schools was similar, with equal probability of encountering one echo type per ESDU. This observation shows a trend of a relative homogenous distribution of school types in different habitats.

\section{Diel schooling dynamics}

School $S v$ values were larger during the night (decrease of $1.79 \mathrm{~dB}$ in Sénégal and $1.28 \mathrm{~dB}$ in Venezuela) as school area decreased during daylight hours. The fish school fractal dimensions also decreased during the day in both countries (Fig. 7). This indicates a trend of fish school expansion at nighttime (Fréon et al. 1996). This expansion is due to increases in nearest neighbour distances between fish inside the schools, produced by less synchronised and/or polarised swimming behaviours (Parrish et al. 2002). Misund et al. $(1992,2003)$ have shown linear relationships between the geometric dimensions and the biomass of fish schools. Our data showed that school surface area increases and school density decreases during the night. At night the average distance to the bottom was higher in Sénégal than in Venezuela, but school morphologies were comparable. Both small pelagic populations presented the same trend of small positive vertical taxis during the night.

Pitcher et al. (1976) have shown that blind fish can school. At night clear schooling structure has been observed in Clupea harengus (Mackinson et al. 1999) many other species (Partridge \& Pitcher 1980, Misund et al. 2003, Bertrand et al. 2004). The diel aggregative dynamics of small pelagic fish are complex and the mechanisms of how light levels affect fish schooling are poorly understood (Woodhead 1966). The classical view assuming that fish are scattering during the night and in schools during the day (see 'Introduction') has yet to be validated by in situ observations, taking into account that the irradiance level depends on school depth, water turbidity, lunar cycle, season and atmospheric conditions such as cloud coverage. The number of schools detected in our 2 study areas revealed an unusual pattern: fish schools were more numerous during the night than by day, although their internal fish school structure was less organised, as Bertrand et al. (2006) observed for Trachurus murphyi off Peru. Feeding (Bertrand et al. 2006), reproduction (Nøttestad et al. 1996), migration (Fernoe et al. 1998), the physiological condition of the fish, their intrinsic sensory perception (Partridge \& Pitcher 1980, Bleckmann 1993) and the presence of predators (Massé et al. 1996) have all been proposed to influence schooling behaviour (Brehmer 2004).

Studying the in situ determinism of diel schooling behaviour is particularly complex. Realistic representation of schooling for small pelagics (Azzali et al. 1985, Seno \& Nakai 1995, Kunz \& Hemelrijk 2003, Hoare et al. 2004, Viscido et al. 2004) is therefore limited. Nevertheless, the formation of schools exclusively during daytime hours has been validated by direct observations reported by several authors. In the Mediterranean Sea, where the bulk of school biomass is composed of sardines and anchovies, schooling has generally been observed during daytime (Iglesias et al. 2003, Muiño et al. 2003) with only very few schools observed at night (Bahri \& Fréon 2000). In the East China and Yellow Seas, Ohshimo (2004) conducted acoustic surveys during daytime because fish schools were considered to be diffused at night. In the Baltic Sea most pelagic fish schools were found at night in scattering layers in a reduced depth range near the surface (Orlowski 2001), which is the same finding as for perch in a freshwater lake in the Alps (Guillard et al. 2004), herring in lake Opeongo (Milne et al. 2005) and anchovies in South Pacific (Gutierrez et al. 2005).

This leads to the assumption that schooling is a common behaviour shared by most pelagic fish species. But schooling behaviour may have different functions 
depending on the species, their life history stage and behavioural motivation. For some species, it is considered to be an 'anti-predator' behaviour, but for others schooling is a predatory behaviour (Bertrand et al. 2004). Some species present variable gregarious behaviour during different life history stages, though most fish can be found schooling during a part of their life. It is then extremely difficult to maintain the idea of a single and general schooling behaviour, even if the inter-individual small scale mechanisms leading to schooling may be the same for all fish

\section{CONCLUSIONS}

In order to someday achieve species recognition of fish schools by remote acoustic methods, it is essential to understand the patterns of schooling behaviour. Species recognition by echo trace discrimination represents a challenge when several species live together in the same ecosystem. In situ schooling dynamics of small pelagic fish schools is variable, although there is a clear behavioural scheme common to a large number of aggregative species. Diel variation in schooling behaviour is most likely the result of complex interactions between the environment and intrinsic fish school characteristics, determined by the effect of the biotic and abiotic environmental characteristics and the possibility of learning (Fig. 8). Schooling behaviour appears to be a phenotypic expression related to behavioural motivation. Modelling aggregative pattern of a single species in a controlled environment and for a small number of individual can be envisaged. Nevertheless in situ schooling measurements appear to be impractical at the present time, since they occur in variable environments, with hundreds of thousands or millions of small pelagic fish individuals per school. Lastly, the schooling behaviour of exploited small pelagic fish can be different inside the same taxonomic fish family, leading to variability in catchability coefficients employed in fisheries management, as demonstrated for the Mediterranean sardine and the Atlantic sardinella. Common adaptive responses of schooling behaviours to the environment are demonstrated by our results, but these could be difficult to interpret in the case of main ecological or anthropical perturbations.

Acknowledgements. This work has been realized through the 'Varget' programme (IRD-FLASA-ISRA) funding by the IRD. We are grateful to L. Gonzales (FLASA, Venezuela) for the echo type extractions from the Venezuelan echogram database, G. Sancho (University of Charleston) for the English revision of this manuscript, and the crew of the RV 'Antéa' for their help at sea. We are grateful to the anonymous referees for their helpful comments.

\section{LITERATURE CITED}

Azzali M, Buracchi G, Conti S, Gambetti S, Luna M (1985) Relationship between the forms of pelagic fish distribution and nycthemeral periods. A tentative model of behaviour. Oebalia 11:471-488

Bahri T, Fréon P (2000) Spatial structure of coastal pelagic schools descriptors in the Mediterranean Sea. Fish Res 48: 157-166

Bertrand A, Barbieri MA, Cordova J, Hernandez C, Gomez F, Leiva F (2004) Diel vertical behaviour, predator prey relationships, and occupation of space by jack mackerel (Trachurus murphyi) off Chile. ICES J Mar Sci 61: 1105-1112

Bertrand A, Barbieri MA, Gerlotto F, Leiva F, Córdova J (2006) Determinism and plasticity of fish schooling behaviour as exemplified by the South Pacific jack mackerel Trachurus murphyi. Mar Ecol Prog Ser 311:145-156

Blaxter JHS, Holliday FG (1969) The behaviour and physiology of herring and other clupeids. Adv Mar Biol 1:261-393

Bleckmann H (1993) Role of lateral line in fish behaviour. In: Pitcher TJ (ed) Behaviour of teleost fishes. Chapman \& Hall, London, p 201-246

Brehmer P (2004) Analyse comparée des caractéristiques dynamiques et spatiales des bancs de Sardinella aurita (Valenciennes, 1847) de diverses populations: adaptations comportementales face à l'environnent et à l'exploitation; effet sur la capturabilité. PhD thesis, Ecole Nationale supérieure d'agronomie de Rennes, Rennes

Brehmer P, Gerlotto F, Rouault A (2002) Inter standardization of acoustics devices: an integrated database for fish school studies. Acta Acoust 88:730-733

Chicki L (1995) Différentiation génétique chez Sardinella aurita et $S$. maderensis. Allozymes et ADN mitochondrial. $\mathrm{PhD}$ thesis, Univ. Paris VI, 16/15/1995

Fernoe A, Pitcher TJ, Melle W, Nøttestad L, Mackinson S, Hollingworth C, Misund OA (1998) The challenge of the herring in the Norwegian Sea: making optimal collective spatial decisions. Sarsia 83:149-167

Fréon P, Mendoza J (eds) (2003) The sardine (Sardinella aurita), its environment and exploitation in eastern Venezuela. IRD, Paris

Fréon P, Misund OA (1999) Dynamics of pelagic fish distribution and behaviour: effects on fisheries and stock assessment. Blackwell, London

Fréon P, Gerlotto, F Soria M (1996) Diel variability of school structure with special reference to transition periods. ICES J Mar Sci 53:459-464

Gerlotto F (1993) Identification and spatial stratification of tropical fish concentration using acoustic populations. Aquat Living Resour 6:243-254

Gerlotto F, Castillo J, Saavedra A, Barbieri MA, Espejo M, Cotel P (2004) Three-dimensional structure and avoidance behaviour of anchovy and common sardine schools in central southern Chile. ICES J Mar Sci 61:1120-1126

Gonzalez L, Gerlotto F, Cardenas JJ (1998) Pelagic fish populations in eastern Venezuela: impact of the environmental characteristics on the morphology, aggregation and spatiotemporal distribution of Sardinella aurita. ICES CM 98/J: 13

Guillard J, Lebourges-Dhaussy A, Brehmer P (2004) Simultaneous $\mathrm{Sv}$ and TS measurements on young-of-the-year (YOY) freshwater fish using three frequencies. ICES J Mar Sci 61:267-273

Gutierrez M, Gerlotto F, Vasquez L, Chipollini A (2005) Anchovy and munida spatio-temporal dynamic and interactions of diel cycles of aggregation. ICES CM 2005/U:22 
Hjellvik V, Godø OR, Tjoestheim D (2004) Diurnal variation in acoustic densities: why do we see less in the dark? Can J Fish Aquat Sci 61:2237-2254

Hoare DJ, Couzin ID, Godin JGJ, Krause J (2004) Contextdependent group size choice in fish. Anim Behav 67:155-164

Iglesias M, Carrera P, Muiño R (2003) Spatio-temporal patterns and morphological characterisation of multispecies pelagic fish schools in the North-Western Mediterranean Sea. Aquat Living Resour 16:541-548

Johannesson KA, Losse GF (1977) Methodology of acoustic estimation of fish abundance in school UNDP/FAO resource survey projects. Rapp Cons Int Explor Mer 170: 296-318

Kunz H, Hemelrijk CK (2003) Artificial fish schools: collective effects of school size, body size, and body form. Artificial Life 9:237-253

Mackinson S, Nøttestad L, Guénette S, Pitcher T, Misund OA, Fernö A (1999) Cross-scale observations on distribution and behavioural dynamics of ocean feeding Norwegian spring-spawning herring (Clupea harengus, L.). ICES J Mar Sci 56:613-626

Marchal E, Petitgas P (1993) Precision of acoustic fish abundance estimates: separating the number of schools from the biomass in schools. Aquat Living Resour 6:211-219

Massé J, Koustikopoulos C, Patty W (1996) The structure and spatial distribution of pelagic fish school in multispecies clusters: an acoustic study. ICES J Mar Sci 53:155-160

Milne SW, Shute BJ, Sprules WG (2005) The schooling and foraging ecology of lake herring (Coregonus artedi) in Lake Opeongo, Ontario. Can J Fish Aquat Sci 62:1210-1218

Misund OA, Aglen A, Beltestad AK, Dalen J (1992) Relationships between the geometric dimensions and biomass of schools. ICES J Mar Sci 49:305-315

Misund OA, Coetzee JC, Fréon P, Gardener M, Olsen K, Svellingen I, Hampton I (2003) Schooling behaviour of sardine Sardinops Sagax in False Bay, South Africa. Afr J Mar Sci 25:185-193

Muiño R, Carrera P, Petitgas P, Beare DJ, Georgakarakos S, Haralambous J, Iglesias M, Liorzou B, Massé J, Reid DG (2003) Consistency in the correlation of school parameters across years and stocks. ICES J Mar Sci 60:164-175

Nøttestad L, Aksland M, Fernö A, Johannessen A, Misund OA (1996) Schooling dynamics of Norwegian spring spawning herring (Clupea harengus, L.) in a coastal spawning area. Sarsia 80:277-284

Ohshimo S (2004) Spatial distribution and biomass of pelagic fish in the East China Sea in summer, based on acoustic surveys from 1997 to 2001. Fish Sci 70:389-400

Orlowski A (2001) Behavioural and physical effect on acoustic

Editorial responsibility: Otto Kinne (Editor-in-Chief), Oldendorf/Luhe, Germany measurements of Baltic fish within a diel cycle. ICES J Mar Sci 58:1174-1183

Parrish JK, Edelstein-Keshet L (1999) Complexity, pattern, and evolutionary trade-offs in animal aggregation. Science 284: 99-101

Parrish J, Viscido S, Nbaum D (2002) Self-organized fish schools: an examination of emergent properties. Biol Bull 202:296-305

Partridge BL, Pitcher TJ (1980) The sensory basis of fish schools: relative roles of lateral line and vision. J Comp Physiol A 135:315-325

Petitgas P, Levenez JJ (1996) Spatial organization of pelagic fish: echogram structure, spatio-temporal condition, and biomass in Senegalese waters. ICES J Mar Sci 53: 147-153

Petitgas P, Reid D, Carrera P, Iglesias M, Georgakarakos S, Liorzou B, Massé J (2001) On the relation between schools, clusters of schools, and abundance in pelagic fish stocks. ICES J Mar Sci 58:1150-1160

Pitcher TJ, Partridge BL, Wardle CS (1976) A blind fish can school. Science 194:963-965

Rose GA, Legget WC (1988) Hydroacoustic signal classification of fish schools by species. Can J Fish Aquat Sci 45: 597-604

Scalabrin C (1997) Identification acoustique des espèces pélagiques à partir d'attributs discriminants des bancs de poissons mono spécifiques. Thesis Doctorale, Université Bretagne Occidentale, Brest

Scalabrin C, Massé J (1993) Acoustic detection of the spatial and temporal distribution of fish shoals in the Bay of Biscay. Aquat Living Resour 6:269-283

Seno H, Nakai K (1995) Mathematical analysis on fish shoaling by a density-dependent diffusion model. Ecol Model 79: 149-157

Shaw E (1961) The development of schooling behaviour in fishes II. Physiol Zool 34:263-272

Simmonds J, MacLennan DN (2005) Fisheries acoustics, theory and practice, 2nd edn. Chapman \& Hall, London

Vabø R, Olsen K, Huse I (2002) The effect of vessel avoidance of wintering Norwegian spring spawning herring. Fish Res 58(1):59-77

Viscido S, Parrish JK, Grunbaum D (2004) Individual behaviour and emergent properties of fish schools: a comparison between observation and theory. Mar Ecol Prog Ser 273: 239-249

Weill AC, Scalabrin C, Diner N (1993) MOVIES-B: acoustic detection description software. Application to shoal species classification. Aquat Living Resour 6:255-267

Woodhead PMJ (1966) The behaviour of fish in relation to light in the sea. Oceanogr Mar Biol Annu Rev 4:337-403

Submitted: April 10, 2006; Accepted: August 16, 2006 Proofs received from author(s): March 13, 2007 